\title{
约 \\ RELAÇÃO ENTRE GESTÃO, MUDANÇA DE GOVERNO, EFETIVIDADE E CONTINUIDADE DOS PROJETOS ESPORTIVOS SOCIAIS \\ RELATIONSHIP BETWEEN MANAGEMENT, GOVERNMENT CHANGE, EFFECTIVENESS AND CONTINUITY OF SOCIAL SPORTS PROJECTS
}

Júnio Braga Borges Silva* Paulo Henrique Azevêdo**

Resumo: A pesquisa abordou a continuidade das políticas públicas sociais esportivas levando em consideração as variáveis (a) gestão financeira, estrutural e de pessoas, (b) mudança de governo e (c) efetividade. Utilizando como objeto de pesquisa o "Programa Segundo Tempo", do Ministério do Esporte, foi identificada a influência desses fatores empregando-se como instrumento de coleta de dados entrevistas semiestruturadas com os principais coordenadores. Os resultados apontaram que essas variáveis foram responsáveis pela continuação dos projetos e também que os valores organizacionais influenciam na forma pela qual o programa é conduzido. Apesar da diminuição do número de convênios abertos no Brasil, não existe previsão de término do "Programa Segundo Tempo", seja por sua importância pedagógica como por seu valor social para a sociedade.

Palavras-chave: Política Pública, Programas Governamentais, Política Social, Segundo Tempo, Esporte.

Abstract: The research addressed the continuity of sports social policies, taking into account the variables (a) financial, structural and people management, (b) change of government and (c) effectiveness. Using as research subject the "Programa Segundo Tempo" ("Second Half Program"), of the Ministry of Sports, it was possible to identify the influence of these factors using this collection's tool semi-structured interviews as main guides. The results indicated that these variables were responsible for the continuation of the projects and also that the organizational values have influence on the way the program is conducted. The variable organization (bureaucracy) appeared as a determining factor in the perpetuation of sports projects and, despite the decrease of the number in agreements opened in Brazil, there is no way to predict the end of the "Second Time Program", which can be due to its pedagogical importance as well as to its valour for the society.

Keywords: Public Policy, Government Programs, Social Policy, Second Time, Sports.

\section{Introdução}

Desde a sua colonização, o Brasil é marcado por períodos de injustiça e desigualdade social que o acompanham até os dias de hoje (HASSENPFLUG, 2004). Como uma das formas de minimizar esses efeitos históricos e possibilitar o acesso democrático às classes

\footnotetext{
* Cursando Especialização em Gestão Pública Municipal na Universidade Aberta do Brasil (UAB-UnB - 2017), formado em Gestão Comercial pela Universidade Católica de Brasília (2010) e Administração pela Universidade de Brasília (2015), realizou intercâmbio na Universidade do Porto - Portugal (2014). Atua na área de Negócios de Impacto Social (junio.unb@gmail.com).

** Possui duas graduações em Educação Física (1985 e 1990). Concluiu o doutorado em Ciências da Saúde (2004) e mestrado em Administração (2002), pela Universidade de Brasília (UnB), onde é Professor Associado. Atualmente é Conselheiro Titular de Notório Saber Esportivo do Conselho de Educação Física, Desporto e Lazer do Distrito Federal - CONEF-DF (pha@unb.br).
} 
marginalizadas da sociedade, o governo brasileiro instituiu as denominadas políticas públicas sociais, que estão presentes nas mais diversas áreas da sociedade, tais como saúde, educação, lazer, cultura e esporte (HÖFLING, 2001). Essas políticas sociais têm como objetivo melhorar a qualidade de vida da população, contribuindo para uma sociedade mais igualitária, com amplo acesso a seus serviços por parte de toda a comunidade. O Estado encontra no aparelho burocrático da administração pública as ferramentas necessárias para a realização dessas políticas, porém existe uma lacuna entre o que se pretende alcançar e o que se alcança verdadeiramente com elas (RUA, 1998). Na maioria das vezes elas não perduram ao longo tempo e, com isso, direitos já adquiridos pela população sofrem retrocesso, não trazendo consigo o amadurecimento dos benefícios sociais já conquistados.

No meio acadêmico vem crescendo o número de pesquisas voltadas para o campo de políticas públicas sociais graças à importância que estas exercem na vida das pessoas e à grande relevância que possuem no desenvolvimento de um país. Na literatura encontramos vários estudos e indicadores (COHEN; FRANCO, 1993; AGUILAR; ANDER-EGG, 1995; SILVA, 2000; HASSENPFLUG, 2004; ARRETCHE, 2007; CABRAL, 2011; CABRAL; MUZY, 2014) que avaliam o impacto causado por essas políticas sociais, e muitos autores citam a continuidade/descontinuidade como um problema dessas políticas (BARROS; CARVALHO, 2003; CARDOSO, 2004; LOBATO, 2004; COUTINHO et al. 2006; CARVALHO et al. 2010; SILVA; 2000; AREIAS; BORGES, 2011; MARCELLINO, 2012). Contudo, não foram encontradas pesquisas voltadas para os fatores que influenciam a continuidade/descontinuidade das políticas públicas sociais e suas relações de causa e efeito. Uma vez que esse impacto foi medido e comprovada a sua efetividade, por que essas políticas não permanecem ao longo do tempo?

Diante desse cenário, essa pesquisa buscou verificar a relação entre gestão dos recursos de pessoas, estruturais e financeiros, mudança de governo e efetividade ${ }^{1}$ e sua influência na continuidade dos projetos esportivos sociais, a fim de que se estabeleçam ações corretivas e futuras políticas possam ser pautadas de forma mais consistente e perene.

\section{Administração Pública}

A Constituição Federal de 1988 preconiza uma administração pública centralizada, enrijecida e hierarquizada, sem foco estabelecido em métricas para alcançar resultados (BRESSER PEREIRA, 2001). Porém, na procura de modernizar o aparelho do Estado, nos deparamos com a necessidade de descentralizar suas atividades como forma de minimizar os efeitos indesejáveis da burocracia, melhorando a qualidade na distribuição dos recursos e

1 A definição de efetividade mostra em que proporção a relação entre os objetivos propostos em um programa e seus resultados foi atingida (BELLONI, 2001). 
expandindo a quantidade de bens e serviços públicos, além de reduzir os custos na prestação dessas atividades (CHEEMA; RONDINELLI, 1983). A descentralização, que se constitui numa ferramenta de modernização da administração pública, procura paralelamente desenvolver uma democracia participativa com o intuito de alcançar maiores graus de eficiência e envolvimento com a sociedade. Surge, então, um novo conceito de gestão pública que tem como referência as mudanças organizacionais que aconteceram no setor privado, trazendo consigo concepções que mudam a maneira burocrática piramidal de gestão, flexibilizando a administração, reduzindo os níveis de hierarquia e ampliando a autonomia de decisão dos gestores. Essas transformações diferem da atual estrutura vigente, que tem normas centralizadoras como base, e abrem espaço para uma outra, firmada na responsabilidade dos agentes e envolvidos, em que o acompanhamento passa a ser da avaliação focada em resultados e no cumprimento dos objetivos efetivamente realizados. Esse novo paradigma procura de forma célere responder às mudanças que ocorrem na economia e na sociedade tendo como base a experiência da iniciativa privada, porém se depara com imensos desafios para adaptar essas ideias e modelos à conjectura política e democrática em que vivemos, no que se refere ao setor público (ENGELMAN; OLIVEIRA, 2012).

Nesse contexto temos um novo marco institucional denominado público não estatal. Diante disso, a definição de público transcende a de Estado e alcança a possibilidade de a sociedade trabalhar em conjunto com o setor público, a fim de prover serviços públicos, seja no acompanhamento ou na operacionalização. Essa nova gestão da administração pública se dispõe a confiar a realização de serviços públicos sociais à esfera pública não-estatal, tornando flexível a gestão pública, gerando com isso vantagens significativas de eficiência e efetividade, sem deixar de lado as premissas básicas do Estado. Nessa variedade de relações, se faz fundamental analisar a estrutura das políticas públicas (ENGELMAN; OLIVEIRA, 2012).

\section{Políticas Públicas e Políticas Sociais}

Quando falamos de políticas públicas e políticas sociais, encontramos na literatura um campo fértil em pleno crescimento que perpassa por diversas áreas científicas do conhecimento, mas ainda com bastante trabalho para se desenvolver. Existe, porém, no meio acadêmico, diferentes definições para o que sejam políticas públicas (SOUZA, 2006). Elas serão definidas aqui como sendo o que Gobert e Muller (1987) chamaram de o "Estado em ação". Para Höfling (2001), é responsabilidade do Estado a implantação de projetos de governo, por meio de programas e atividades, com enfoque em setores específicos da sociedade. Também é sua atribuição executar e manter essas incumbências junto a órgãos públicos, diferentes organismos e agentes da sociedade vinculados à política implementada, e políticas sociais como ações que vão determinar o nível de proteção social praticada pelo Estado, voltadas principalmente para o acesso democrático dos benefícios sociais, com o objetivo de minimizar as desigualdades 
estruturais causadas pelo desenvolvimento socioeconômico.

As políticas sociais surgem nos movimentos populares do século XIX, ligadas aos conflitos que apareceram em relação ao capital e trabalho, no surgimento das primeiras revoluções industriais (HÖFLING, 2001). Elas possuem uma localização especial no conjunto das políticas públicas, principalmente no Brasil, em que existe uma forte estrutura de proteção social que convive com níveis gigantescos de desigualdade e exclusão social (LOBATO, 2004). As políticas iniciadas pelo governo não se implementam sozinhas; acontecem mudanças, existem conflitos e podem ter resultados divergentes do proposto, especialmente por estarem ligadas a grupos heterogêneos, e o impacto das suas ações pode ter influência direta nas dinâmicas sociais de poder (HÖFLING, 2001).

Quando nos referimos ao Brasil no quesito desenvolvimento de políticas sociais, encontramos um conjunto amplo e bastante variado, porém descontínuo e insuficiente para a população (SILVA; SILVA, 2000). Segundo HÖFLING (2001), essas políticas são diversas, complexas e exigem um grande esforço para analisar os fatores envolvidos responsáveis pelo sucesso ou fracasso. Mais do que ter um crescimento sofisticado em métodos, instrumentos avaliativos de programas e projetos e até das próprias políticas, é primordial levar em consideração as questões que permeiam o seu redor, ou seja, o meio onde elas estão sendo realizadas, pois é a partir daí que conseguimos obter informações para a tomada de decisão, escolher os caminhos de implementação a serem traçados e os modelos de avaliação a serem aplicados. Para analisarmos e avaliarmos as políticas públicas de fato realizadas por um governo, também devemos levar em consideração a natureza dos diferentes fatores envolvidos, como economia, desigualdade social, cultura local, outras políticas etc.

\section{Continuidade das Políticas Públicas}

A não continuidade das políticas públicas sociais é algo presente no discurso acadêmico quando falamos de políticas (LOBATO, 2004). Porém, pouco se fala ou se sabe verdadeiramente sobre quais fatores influenciam de fato a descontinuidade delas. Os autores Barros e Carvalho (2003) destacam alguns desafios que merecem atenção quanto à perenidade das políticas sociais. Em primeiro lugar, essas políticas precisam ser flexíveis, uma vez que a desigualdade é um tema global, porém a sua solução é tipicamente local. Em segundo lugar, as políticas necessitam de efetividade, pois a continuação delas depende enormemente do grau de envolvimento e cooperação dos agentes que nela atuam.

Enfrentar desafios para que as políticas públicas permaneçam ao longo do tempo não é uma tarefa fácil, porém é um dos principais caminhos para criar ou facilitar ações corretivas, a fim de que futuras políticas possam ser pautadas de forma mais consistente e que se perpetuem. Uma das possíveis alternativas a seguir pode ser a sumarização daquilo que já sabemos sobre o seu sucesso e fracasso, de maneira que possamos aprender com os erros do passado, 
potencializar os acertos realizados, pois a similaridade dos programas realizados no mundo inteiro, com diferentes convicções ideológicas de governo e organizações não governamentais (ONGs) das mais variadas frentes, leva a pensar que o planejamento está quase sempre se repetindo, e dessa forma o que não existe é uma análise coesa dos princípios atribuídos aos projetos e as metodologias utilizadas (CARDOSO, 2004).

Além dos desafios acima encontrados, destacam-se os seguintes aspectos como fatores que influenciam a continuidade das políticas públicas:

$\checkmark \quad$ Independentemente de qualquer que seja a área da política pública e sua estrutura formal de poder, as pessoas envolvidas são responsáveis diretas pelo sucesso ou não, pois se as mesmas perceberem e entenderem, mobilizarão recursos de onde quer que seja necessário para enfrentar os desafios encontrados, mesmo que estes sejam "insuperáveis" (CARVALHO et al. 2010).

$\checkmark$ Um dos grandes problemas para a continuidade das políticas públicas são as mudanças de dirigentes, ou seja, como a troca de governo é frequente, ocorre o abandono dos projetos antigos com a entrada de uma nova direção (CARDOSO 2004).

$\checkmark$ Um dos grandes entraves para o bom andamento das políticas sociais é a gestão de pessoas, pois a escolha dos profissionais envolvidos no projeto, a falta de pessoal especializado e a não estruturação definida de cargos e funções acarretam um certo tipo de degradação das atividades no longo prazo (MARCELLINO, 2012), além, é claro, de ser necessária uma boa qualificação/capacitação dos trabalhadores envolvidos para o bom funcionamento das políticas públicas de lazer (AREIAS; BORGES, 2011).

$\checkmark$ O tipo de projeto social e o seu modelo gerencial influenciarão de alguma maneira a efetividade, satisfação dos interessados e a sustentabilidade dos projetos (fatores de desempenho), ainda que isso de fato não seja suficiente para justificar o desempenho do projeto como um todo (COUTINHO et al. 2006).

$\checkmark$ A falta de recurso gera uma estrutura física precária e materiais necessários insuficientes (AREIAS; BORGES, 2011), sendo também a fuga de recursos do público-alvo para outros grupos um dos responsáveis pelos fracos resultados alcançados (CARDOSO, 2004).

Diante dos desafios encontrados elaboramos a seguinte representação esquemática: 


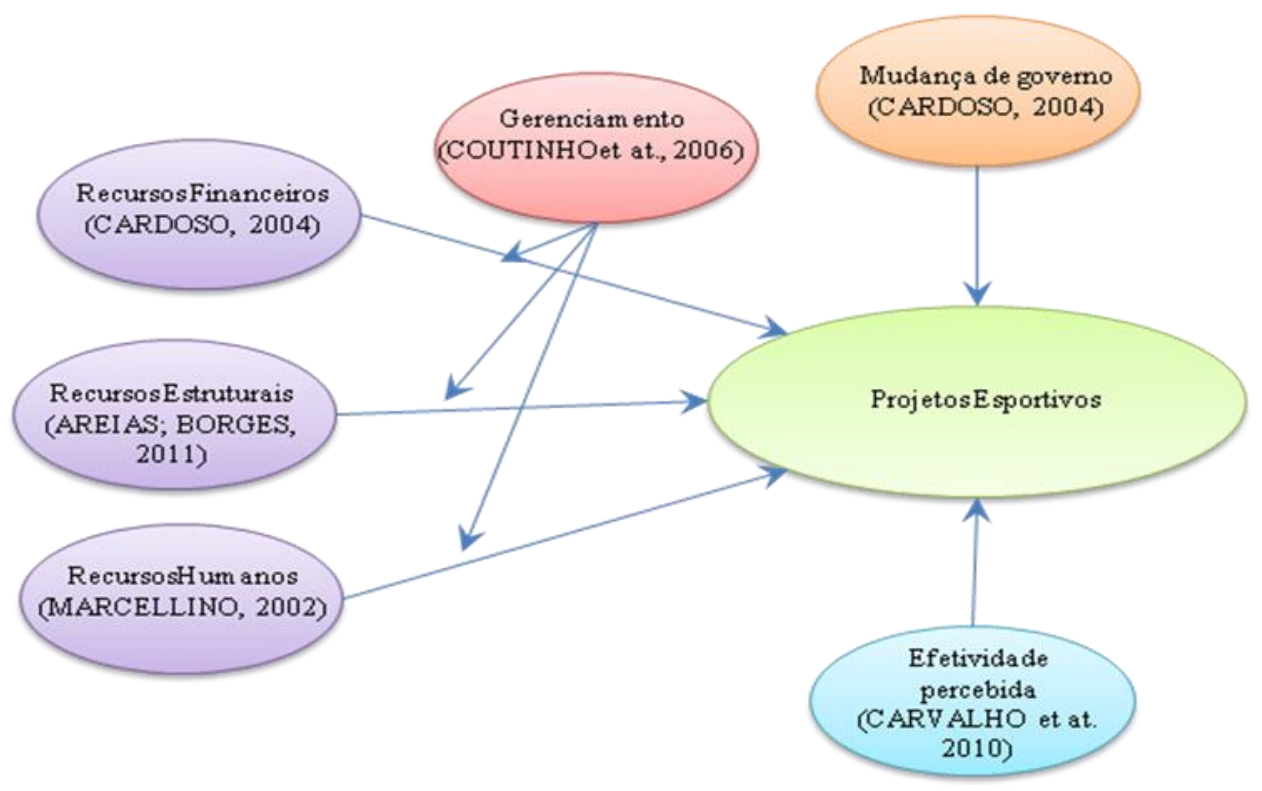

Figura 1 - Representação esquemática sobre as variáveis do estudo e suas possíveis

Fonte: o autor relações

\section{Programa Segundo Tempo}

Segundo o Manual de Diretrizes do Programa Segundo Tempo - PST (ME, 2014), esse programa é uma ação do Ministério do Esporte (ME) que objetiva facilitar o acesso à cultura de atividades referentes ao esporte educacional, disseminando o desenvolvimento pleno de crianças, adolescentes e jovens para formação cidadã e a melhoria da qualidade de vida, dando prioridade àqueles que estão em áreas de risco social, matriculados na rede de ensino público. $\mathrm{O}$ Segundo Tempo faz parte da Ação Orçamentária 20JP, que estabelece o desenvolvimento de ações e suporte a projetos de educação esportiva, lazer e inclusão social com a finalidade de implementar atividades de esporte para o seu público-alvo, ofertando diversas oportunidade de vivências no esporte e outras práticas, com foco em áreas de vulnerabilidade social, financiando e formando pessoas, recebendo e ofertando material didático e didático-esportivo, além de outros gastos, através da criação de núcleos esportivos para que os beneficiários se desenvolvam por completo.

O PST foi lançado oficialmente em 2003, por meio da celebração de protocolo de cooperação entre os ministros do Esporte (Agnelo Queiroz) e da Educação (Cristovam Buarque). Na época, essa parceria representava o que o governo federal queria de seus ministérios - políticas articuladas e intersetoriais -, e também procurava suprir a demanda do programa junto às estruturas das escolas públicas, onde o aluno pudesse passar mais tempo nas escolas e utilizar o esporte como instrumento de socialização. A realização das atividades do programa é feita de forma descentralizada, por meio de convênios assinados entre as entidades públicas e o ME (ATHAYDE, 2009), que estabelece núcleos de atendimentos para o programa. 
Cada núcleo tem que atender a algumas especificações:

- Quantidade de beneficiários: entre 70 e 100 crianças, adolescentes e jovens, principalmente em situação de vulnerabilidade social.

- Desenvolvimento das atividades: mínimo de 3 modalidades esportivas, 3 horas por dia, ou 3 vezes por semana com duas horas por dia.

- Turmas: mínimo de 3 turmas por núcleo e máximo de 35 alunos por turma.

- Carga horária: grade horária para que cada professor e monitor atendam a 3 turmas em locais diferentes.

As entidades que recebem o Programa devem oferecer a estrutura esportiva necessária para a realização das atividades, que podem ocorrer na escola e/ou em locais próximos, de preferência que não necessitem da utilização de condução para os beneficiados. Os locais precisam ser adequados para as atividades que serão ofertadas e para a quantidade de usuários atendidos, além da necessidade de ter as condições mínimas básicas de atendimento, como banheiro, bebedouros e área para atividades complementares. Os profissionais envolvidos por projeto são: coordenador-geral, coordenador pedagógico e coordenador setorial. Cada núcleo deve ter profissional/professor de educação física ou esporte e acadêmico de educação física ou esporte, cada um com sua devida atribuição e responsabilidade. Esses profissionais recebem capacitação e treinamento para identificar as diretrizes do PST e sua base teórica e entender como elas guiam as práticas pedagógicas no dia a dia. O Ministério do Esporte coloca à disposição os recursos e sugere itens para as compras de materiais de qualidade para estimular a realização das atividades de forma contínua, adequada e de qualidade, além de definir bem claro as responsabilidades entre ele e as instituições que realizam o convênio (BRASIL, 2014).

\section{Métodos e Técnicas de Pesquisa}

Esta etapa do projeto de pesquisa está estruturada em três estágios: pesquisa bibliográfica, coleta e análise de dados.

A pesquisa pode ser classificada em bibliográfica, documental, de campo e descritiva/ exploratória (RICHARDSON et al., 1999) com abordagem qualitativa e quantitativa.

A pesquisa caracteriza-se como de campo, pois coletou dados junto aos principais coordenadores do programa esportivo Segundo Tempo, do Ministério do Esporte, e excoordenadores locais dos respectivos projetos no Distrito Federal por meio de uma entrevista semiestruturada. (CRESWELL, 1994).

No que tange a parte de análise quantitativa, esta foi realizada com base em dados obtidos no próprio Ministério do Esporte, no que se refere à quantidade de convênios, atendimentos, núcleos, professores e outros.

A pesquisa bibliográfica abordou os temas desigualdade social, políticas públicas, projetos sociais, projetos sociais esportivos, políticas sociais, relevância econômica dos 
esportes, Segundo Tempo, implementação de políticas e avaliação de projetos sociais.

O objeto de estudo é um programa social esportivo do Ministério do Esporte denominado Segundo Tempo, presente atualmente em 22 estados brasileiros e no Distrito Federal, criado em 2003.

Foi uma amostragem de conveniência, sendo entrevistados um coordenador do programa Segundo Tempo, no Ministério do Esporte, um coordenador nacional e um excoordenador local de projeto em Brasília. A fim de preservar as informações obtidas, optamos por omitir os nomes dos entrevistados, substituindo-os, respectivamente, por: Coordenador 1 , Coordenador 2 e Coordenador 3.

Foram elaborados dois roteiros de entrevistas semiestruturadas, sendo o primeiro para entidades conveniadas com o Programa Segundo Tempo, e o segundo, para os coordenadores do programa no Ministério do Esporte, contendo 25 questões em ambos, sendo 17 perguntas iguais e 8 específicas para a entidade (Ministério do Esporte e conveniadas). A elaboração foi feita a partir de pesquisa bibliográfica realizada, de dados empíricos e de entrevista geral com um coordenador no Ministério do Esporte, levando em consideração as variáveis do estudo. O instrumento aborda: dinâmica de funcionamento e características dos projetos; conteúdos, mudança de governo, processos de gestão financeira, estrutural e de pessoas; aspectos que influenciam o funcionamento e alcance de resultados dos projetos esportivos; estrutura e características relacionais dos projetos; desempenho e continuidade dos projetos.

A análise documental levantou dados junto a fontes secundárias (Ministério do Esporte, outros trabalhos) para identificar os projetos esportivos, a quantidade de projetos realizados e os que não estão mais em funcionamento, de modo a viabilizar a coleta de dados junto a esses coordenadores.

A definição dos projetos locais a serem pesquisados foi feita a partir da identificação de características e acessibilidade, buscando assegurar a representatividade dos projetos nas diversas áreas do território do Distrito Federal, bem como de eventuais diferenças identificadas nos projetos (tempo de existência, número de integrantes, área de atuação, entre outras), além de buscar diferentes visões dos entrevistados, sendo uma do próprio Ministério do Esporte, outra de um convênio em funcionamento e de um que não está mais ativo.

Os dados foram submetidos à análise de conteúdo.

Os resultados obtidos junto aos coordenadores de diferentes instituições foram analisados e comparados entre si.

\section{Resultados e discussão}

Buscamos no presente trabalho uma amostra de conveniência abrangendo agentes envolvidos no Programa Segundo Tempo, composta por dois doutores e um especialista. Os 
coordenadores entrevistados são pessoas que exercem ou exerceram cargo de grande responsabilidade no programa, sendo estes os principais responsáveis pelo funcionamento do PST em sua instituição. Todos os entrevistados ainda atuam de alguma maneira no programa e demonstraram durante as entrevistas bastante conhecimento sobre o mesmo, bem como pleno domínio sobre as normas, diretrizes, regras, funcionamento e gestão do Programa Segundo Tempo como um todo, além também de já terem conhecimento prévio adquirido em participação em outros programas sociais esportivos.

Para melhor compreensão dos acontecimentos do programa é apresentado abaixo um breve resumo histórico dos principais fatos ocorridos ao longo dos seus 13 anos de existência, segundo informações relatadas pelos próprios entrevistados.

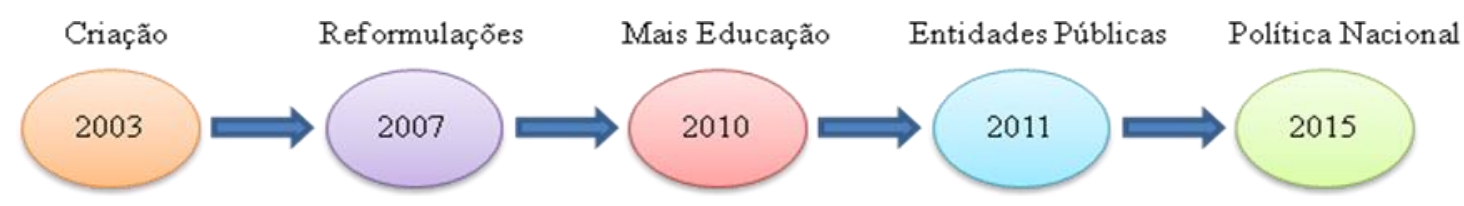

Figura 2 - Marco Histórico do Programa

Fonte: Elaboração própria a partir das entrevistas

2003: Criação do programa para o Plano Plurianual do Governo Federal 2004/2007 (Coordenador 1) em parceria com diversos outros ministérios e o Programa Pintando a Liberdade, que fornecia o material para prática esportiva (Coordenador 2).

2007: O programa sofre grandes reformulações, entre elas, inclusão da formação de equipes colaboradoras em parcerias com grandes universidades no Brasil (Coordenador 1).

2010: O Ministério do Esporte faz parceria com o Programa Mais Educação, do Ministério da Educação, a fim de ampliar a oferta do programa. (Coordenador 1)

2011: A partir desse ano só entidades públicas podem pleitear a participação no Programa (Coordenador 1).

2015: Está em tramitação a proposta de criação de um Sistema Nacional de Esporte e Lazer (Coordenador 1).

Em 2007, além das parcerias com universidades públicas relatadas acima, houve também a publicação de um novo manual, que reformulava o conceito do Programa Segundo Tempo com a inclusão de outros objetivos, reiterando o foco no esporte educacional e desfazendo algumas parcerias (ATHAYDE, 2009). Outro ponto que merece atenção foi que, em 2011, só entidades públicas poderiam fazer o convênio com o Ministério do Esporte (Coordenador 1). Parte disso se deve ao desvio de verbas que vinha ocorrendo por meio de algumas organizações não governamentais (ONGs), o que afetou a imagem do programa perante a sociedade (Coordenador 3). Cabe ressaltar que, durante a execução do Segundo Tempo, as ONGs representavam uma parcela significativa dos convênios realizados até então com o ME (21\%), perdendo apenas para os municípios (66\%), seguidos em número de 
convênios realizados pelos governos estaduais (8\%) e pelo governo federal (5\%). Por último encontramos um convênio realizado por meio de uma emenda $(0 \%)$, conforme gráfico representativo abaixo.

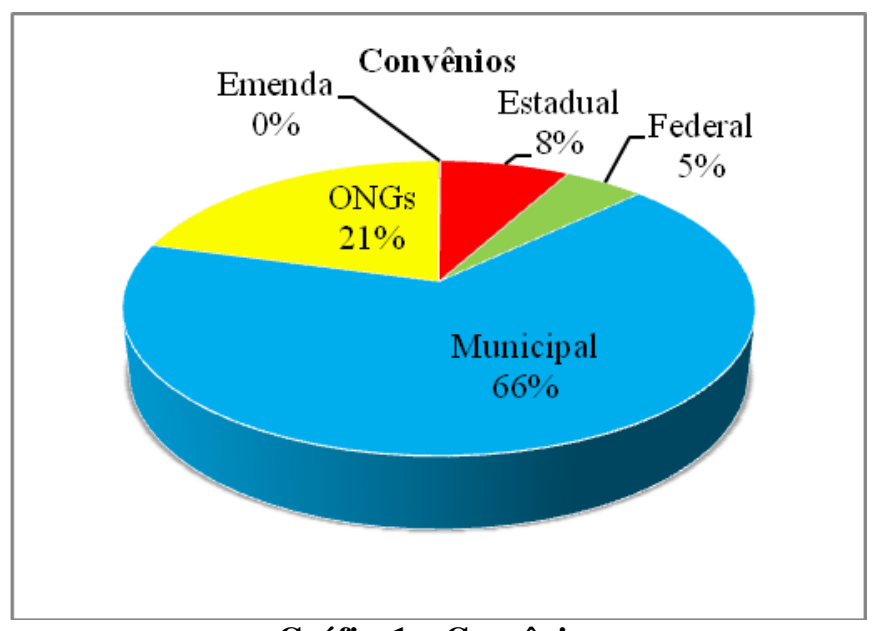

\section{Gráfico1 - Convênios}

Fonte: Elaboração própria a partir dos dados do Ministério do Esporte

Quando nos referimos a número de crianças e adolescentes atendidos por esses convênios, essa representatividade se altera. As ONGs e governos estaduais passam a ter uma maior porcentagem de atendimentos, de $21 \%$ para $34 \%$ e de $5 \%$ para $24 \%$, respectivamente, enquanto os governos municipais e federal diminuem sua parcela, de $66 \%$ para $40 \%$, e $5 \%$ para $2 \%$, respectivamente. Porém a ordem de maior representação para a menor continua a mesma, governo municipal em primeiro lugar (40\%), ONGs em segundo (34\%), governo estadual (24\%), governo federal (2\%) e, por último, Emenda (0\%), conforme o Gráfico 2:

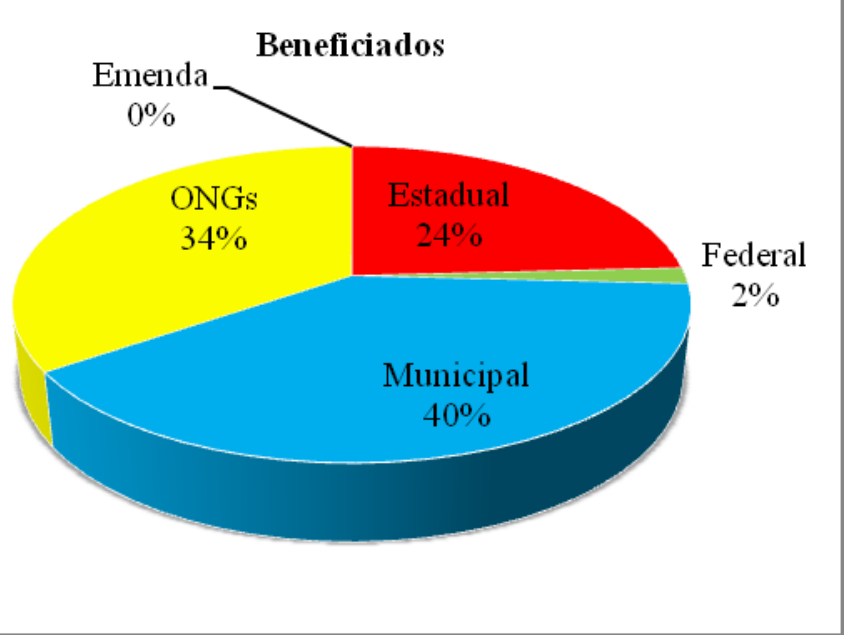

Gráfico2 - Beneficiados

Fonte: Elaboração própria a partir dos dados do Ministério do Esporte

Essa comparação (convênios x beneficiados) nos mostra convênios onde existem mais crianças e adolescentes sendo atendidas pelo programa em relação a outros. Um dos possíveis motivos para que isso ocorra pode ser devido às exigências do próprio programa, pois, 
conforme consta no Manual de Diretrizes (2014), cada núcleo tem que atender entre um número mínimo e máximo de beneficiados do programa.

O Programa Segundo Tempo é um programa de grande repercussão no Brasil e no mundo, e seus resultados durante toda a sua trajetória mostram isso, conforme quadro abaixo:

Tabela 1 - Trajetória e atualidade do Segundo Tempo em números

\begin{tabular}{cccccc}
\hline PST & Convênios & Atendimento & Núcleos & Coordenadores & Monitores \\
\hline 2015 & 158 & 287.900 & 2.570 & 3.160 & 3.669 \\
Todo o PST & 1128 & 3.961 .106 & 22.793 & 23.997 & 50.111 \\
\hline Total & $\mathbf{1 2 8 6}$ & $\mathbf{4 . 2 4 9 . 0 0 6}$ & $\mathbf{2 5 . 3 6 3}$ & $\mathbf{2 7 . 1 5 7}$ & $\mathbf{5 3 . 7 8 0}$ \\
\hline
\end{tabular}

Fonte: Elaboração própria a partir dos dados do Ministério do Esporte

Esses números refletem claramente o discurso do Coordenador 1 sobre importância do segundo tempo: “...ele é, no âmbito social, o principal programa do Ministério, tanto em renovação de recursos como em abrangência...".

Ao longo da sua história, o Programa Segundo Tempo já atendeu quase quatro milhões de crianças e adolescentes em seus quase 23 mil núcleos espalhados pelo Brasil inteiro. Isso se dá graças às parcerias (convênios) estabelecidas com instituições durante os anos de existência, e todos saem ganhando: sociedade, profissionais, organizações, o esporte e principalmente as crianças e adolescentes. O gráfico abaixo traz essa relação de parcerias por meio do número de convênios abertos e encerrados durantes os anos de 2003 a 2017. Vale ressaltar que os convênios agora estabelecidos têm a duração de 26 meses, sendo quatro meses para estruturar o programa e o restante para sua execução, podendo essa parceria ser prorrogada ou não (Coordenador 1), por isso nossa análise será feita até o ano de 2017, devido às parcerias firmadas até agora, em 2015. 


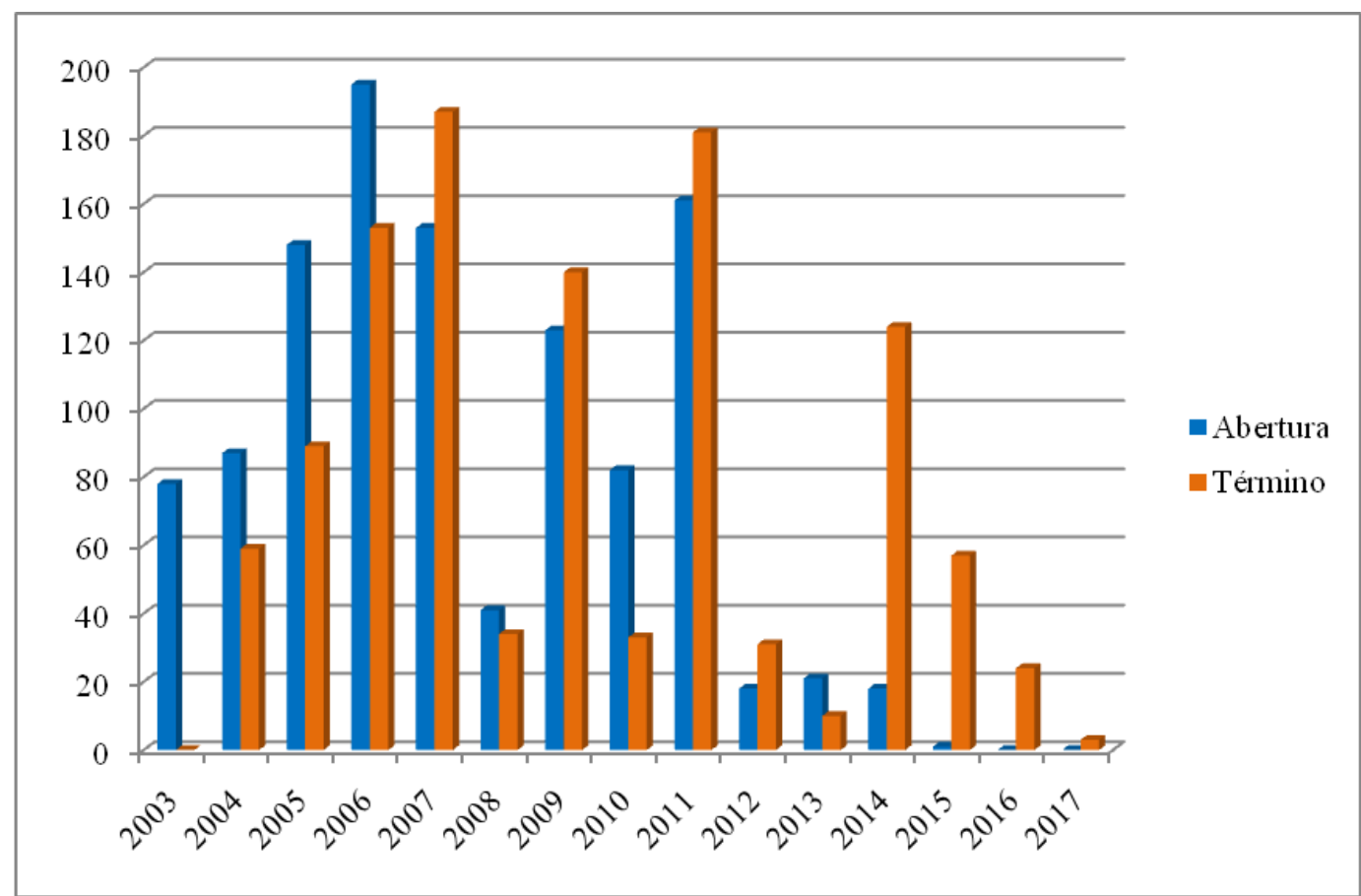

Gráfico 3 - Abertura e término de convênios no Brasil

Fonte: Elaboração própria a partir dos dados do Ministério do Esporte

Como podemos ver, de 2003 até 2006, o número grande de convênios abertos em todo o Brasil é maior do que o de encerrados. A partir de 2007 até 2009, com as mudanças ocorridas, esses números se invertem e o encerramento de convênios acaba sendo maior que o de abertura. Nos anos seguintes há oscilações: em 2010 a abertura ultrapassa o fechamento; em 2011 e 2012 o encerramento é que excede a abertura; em 2013 o número de aberturas volta a superar o fechamento e, por fim, em 2014, por uma grande diferença, o número de fechamentos passa o de abertura. Acrescentando à nossa analise a variável eleição presidencial, de 2006 e 2010², a marca de abertura é maior que a de fechamento, porém essa série não se repete em 2014, o que nos levaria a pensar que, caso o número de abertura fosse maior que o de fechamento também em 2014, o governo poderia estar utilizando o PST como uma forma de tentar se reeleger, porém, como podemos ver, essa hipótese não se confirma. Buscamos aqui também verificar o número de projetos abertos e fechamento sob a ótica do Produto Interno Bruto (PIB) ${ }^{3}$ brasileiro para identificar se existe correlação entre os dois. Nessa análise estatística, a correlação se mostrou fraca, assumindo o valor $P=-0,31491$ quando nos referimos a PIB x Abertura de convênios, e de $P=0,032466$ em PIB x Fechamento. Esses resultados vão ao encontro das críticas que o PIB vem sofrendo por parte de importantes agentes da sociedade (acadêmicos, políticos, formadores de opnião e etc) (FEIJÓ et al, 2012), de que o mesmo não mede desenvolvimento social.

Apesar de sua importância histórica, é bastante claro que o programa vem sofrendo uma

\footnotetext{
${ }^{2}$ Cronologia das Eleições no Brasil (1945 - 2010)

${ }^{3}$ BANCO MUNDIAL. PIB
} 
queda a partir de 2011, sendo constatada uma diminuição expressiva no ano de 2014 e um dos possíveis motivos para essa grande redução seja a prioridade que o governo brasileiro e o Ministério do Esporte vêm dando aos megaeventos que estão ocorrendo no Brasil - dentre eles cabe destacar a Copa do Mundo de 2014 e as Olimpíadas que vão ocorrer em 2016 (Coordenador 1).

Pensar na continuidade do programa nos leva a analisar e questionar sobre o que o cerca e as variáveis que o influenciam. Como pode ser visto no manual de diretrizes 2014 do PST, o Ministério do Esporte também está preocupado com vários desses questionamentos que permeiam o Segundo Tempo, tais como definição do programa, público-alvo, princípios, objetivo geral, objetivos específicos, fundamentação pedagógica, retorno esperado, estruturação, formação, profissionais, responsabilidade, despesas, gestão, prestação de contas etc. Porém, verificamos, por meio das entrevistas, que apesar de os coordenadores conhecerem a fundo todas essas normas e princípios, o ambiente (valores organizacionais) da instituição que estabelece o convênio com o Ministério do Esporte, seja ela militar, religiosa, escolar ou outra, irá influenciar também na formação dos participantes. Essa relação fica bastante clara nos trechos retirados das entrevistas, quando os entrevistados são questionados:

No seu entendimento, quais são os pontos positivos do Programa Segundo Tempo?

“.... o foco para nós, no Segundo Tempo, é você possibilitar as múltiplas vivências da criança e adolescente à prática esportiva ..." (Coordenador 1)

“...é evasão escolar, aumento da nota escolar, amor ao Brasil, à pátria brasileira, uma disciplina, com isso diminuindo o grau de violência junto à sociedade e na família; e esperança em alcançar os objetivos e que seja incluido socialmente...” (Coordenador 2)

“....é um espaço para prática pedagógica para os alunos aplicarem na prática aquilo que eles aprendem na sala de aula..." (Coordenador 3)

Encontramos, assim, três diferentes visões dos resultados do Programa. O primeiro (Coordenador 1), com visão para a vivência das crianças no esporte. O segundo (Coordenador 2), mais focada nos resultados alcançados. Já o terceiro (Coordenador 3), voltado à formação dos indivíduos (professores). Todos os coordenadores deixaram bem claro que o principal objetivo é possibilitar o acesso ao esporte para crianças, adolescentes e jovens. Mesmo assim, parte de como eles veem o Segundo Tempo se dá por conta das instituições a que pertencem, e por mais que o Programa tenha regras e diretrizes bem definidas, estas são influenciadas pelas instituições conveniadas. Então, a formação dos participantes sofrerá influência também pelos valores das organizações conveniadas, merecendo uma atenção especial por parte do Ministério do Esporte para que essa visão não comprometa o objetivo proposto do programa. 


\section{Considerações Finais}

O modelo proposto da representação esquemática (Figura 1) sobre as variáveis do estudo e suas possíveis relações (gestão, mudança de governo e efetividade) confirmou-as como sendo responsáveis pela continuidade do programa.

Além das variáveis propostas inicialmente nos estudos - recursos estruturais, recursos financeiros, recursos humanos, gerenciamento, mudança de governo e efetividade -, foi identificada por meio das entrevistas a variável "burocracia" como fator determinante para a continuidade/descontinuidade do Programa Segundo Tempo.

Não foi encontrada relação entre abertura/fechamento dos projetos com anos eleitorais para presidente, logo, não podemos afirmar que o governo venha utilizando dessa política como manobra para se manter no poder. Partindo para uma análise sob a ótica econômica, não encontramos relação do PIB e a abertura/fechamento dos projetos nos anos 2003 a 2013, e isso corrobora as críticas que grandes autores fazem ao PIB como medida de desenvolvimento de um país.

Percebemos que as atividades nos núcleos do PST sofrerão influência dos valores organizacionais das instituições conveniadas com o ME.

Como fator limitante do estudo está a quantidade de entrevistados, que foi restrita, porém significativa. Mesmo assim, não inviabilizou a pesquisa e os seus resultados.

Para futuros estudos e pesquisas, sugerimos que seja replicado o modelo em outras regiões do Brasil, com uma amostra maior, além de incluir a variável burocracia, a fim de estabelecer uma comparação com os resultados encontrados.

Concordamos com os estudos de Cardoso (2004), que concluem que um dos caminhos para se realizar políticas mais eficientes é conhecer as variáveis que afetam o seu funcionamento, tanto positiva como negativamente, para que possam [as políticas] se manter durante o tempo.

Sendo assim, o Programa Segundo Tempo terá sua duração prolongada devido a sua importância social, à relevância dada pelo próprio Ministério do Esporte e às constantes mudanças necessárias que nele vêm ocorrendo, como constatamos claramente no discurso dos entrevistados. Mesmo que hoje o Programa esteja em diminuição, parte disso se devendo ao foco que o Ministério tem dado aos megaeventos que ocorreram ou vão ocorrer no Brasil (Copa do Mundo e Olimpíadas), conforme entrevistas e segundo dados do próprio ME, pelo menos até 2017 ainda teremos convênios ativos e esperamos que essa política se prolongue por mais tempo, pois podemos identificar por meio do trabalho seus benefícios para a sociedade. 


\section{Referências}

AGUILAR, M. J.; ANDER-EGG, E. Avaliação de Serviços e Programas Sociais.2. ed. Petrópolis: Vozes, 1995.

AREIAS, K. T. V.; BORGES, C. N. F. As políticas públicas de lazer na mediação entre Estado e Sociedade: possibilidades e limitações. Rev. Bras. Ciênc. Esporte, Florianópolis, v. 33, n. 3, p. 573-588, jul./set. 2011

ARRETCHE, M. T. S. Tendências no estudo sobre avaliação. In: RICO, Elizabeth Melo (org.). Avaliação de políticas sociais: uma questão em debate. 6.ed. São Paulo:Cortez:Instituto de Estudos Especiais, 2007, p. 29-39.

ATHAYDE-FILHO, P. F. Programa segundo tempo - conceitos, gestão e efeitos. Dissertação (Mestrado) - Faculdade de Educação Física, UnB, Brasília, 2009

BARROS, R. P.; CARVALHO, M. Desafios para a política social brasileira. Rio de Janeiro: Ipea, 2003.

BELLONI, I.; MAGALHÃES, H.; SOUSA, L. C. Metodologia para avaliação de políticas públicas: uma experiência em educação profissional. São Paulo: Cortez, 2001. 96 p. (Coleção Questões da Nossa Época, v. 75).

BRESSER-PEREIRA, L. C. Uma nova gestão para um novo estado: liberal, social e republicano. Revista do Serviço Público, Ottawa, v. 52, n. 1, p. 5-24, jan. 2001.

BRASIL. MINISTÉRIO DO ESPORTE. Manual de Diretrizes do Programa Segundo Tempo. Brasília: ME, 2014.

BRASIL. MINISTÉRIO DO ESPORTE. Mapa de distribuição. Disponível em: http://www.seguro.esporte.gov.br/segundotempo/mapaConvenio.asp. Acesso em: 21 abril 2015.

BRASIL. MINISTÉRIO DO ESPORTE. Política Nacional do Esporte. Brasília: ME, 2005. 44 p.

CABRAL, E. H. S. Valores e espaço público: referenciais e instrumentos para a avaliação de projetos sociais. Rev. Adm. Pública, v. 45, n. 6, p. 1915-1941, nov./dez. 2011.

CABRAL, E. H. S.; MUZY, P. T. Os valores e o valor da moeda: hipóteses sobre a comensurabilidade e a monetarização do impacto de projetos sociais. Cad. EBAPE.BR, v. 12, $\mathrm{n}^{\circ}$ 2, artigo 9, Rio de Janeiro, Abr./Jun. 2014.

CARDOSO, R. Sustentabilidade, o desafio das políticas sociais no século 21. São Paulo em perspectiva, 18(2) 2004.

CARVAlHO, M. L.; BARBOSA, T. R. C. G.; SOARES, J. B. Implementação de Política Pública: uma abordagem teórica e crítica. Mar del Plata: X Coloquio Internacional sobre Gestión Universitaria en América Del Sur, Diciembre de 2010.

CHEEMA, G. S.; RONDONELLI, D. A. A descentralization and development. Beverly Hills. London, New Delli: SagePublications, 1983.

COHEN, E.; FRANCO, R. Avaliação de Projetos Sociais. Petrópolis: Vozes, 1994. 
COUTINHO, R. B. G. ET AL. Projetos sociais de empresas no Brasil: arcabouço conceitual para pesquisas empíricas e análise gerenciais. RAP Rio de Janeiro 40(5):763-87, Set./Out. 2006

CRESWELL, J. W. Research design: qualitative and quantitative approaches. Thousand Oaks, CA: Sage, 1994

ENGELMAN, S.; OLIVEIRA, A. A. B. Gestão pública em rede: o caso do programa segundo tempo - ministério do esporte. Rev. Educ. Fis/UEM, v. 23, n. 4, p. 543-552, 4. trim. 2012

FEIJÓ, C. A. ET AL. Além do PIB: uma visão crítica sobre os avanços metodológicos na mensuração do desenvolvimento sócio econômico e o debate no Brasil contemporâneo. Estatística e Sociedade, Porto Alegre, p. 42-56, n.2, nov, 2012.

GOBERT, M. IN, VAZ, L. G. D. Políticas públicas. Revista nova Atenas de educação e tecnologia. Revista eletrônica do departamento. Acadêmico de ciência da saúde Educação física e esportes - Biologia - Segurança do trabalho. Vol. 10, nº. 01, jan./jun./2007.

HASSENPFLUG, W. N.. Educação pelo esporte: educação para o desenvolvimento humano pelo esporte. São Paulo: Saraiva; 2004.

HÖFLING, E. M. Estado e políticas (públicas) sociais. Cadernos Cedes, ano XXI, $\mathrm{n}^{\circ}$ 55, novembro/2001.

LOBATO, L. V. C. Avaliação de políticas sociais: Notas sobre alguns limites e possíveis desafios. Trabalho, Educação e Saúde, 2(1): 239-265, 2004.

MARCELlinO, N. C. Estudos do lazer: uma introdução. 5. Ed. Campinas: Autores Associados, 2012.

BANCO MUNDIAL. PIB. Disponível em: $<$ https://www.google.com.br/publicdata/explore?ds=d5bncppjof8f9_\&ctype=1\&strail=false \&bc $\mathrm{s}=\mathrm{d} \& n s e l m=h \& m e t \_\mathrm{y}=\mathrm{ny} \_g d p \_m k t p \_c d \& s c a l e \_\mathrm{y}=$ lin\&ind_y=false\&rdim=region\&idim=count ry:BRA:MEX:RUS\&ifdim=region\&hl=pt\&dl=pt\&ind=false>. Acesso em 09 de Março de 2016

RICHARDSON, R. J.. et al. Pesquisa social: métodos e técnicas. 3.ed. São Paulo: Atlas,1999.

RUA, M. G. Análise de políticas públicas: conceitos básicos. In: RUA, Maria das Graças; VALADÃO, Maria Izabel. de (Orgs.). O estudo da política. Brasília: Paralelo 15, 1998.

SILVA E SILVA, M. O. Execução e Avaliação de Políticas e Programas Sociais. In: CFESS/ABEPSS/CEAD/UnB. Capacitação Continuada em Serviço Social e Política Social, Módulo 4. Brasília, UnB, 2000.

SOUZA, C.. Políticas Públicas: uma revisão da literatura. Sociologias, Porto Alegre, ano 8, no 16, jul/dez 2006, p. 20-45.

TRIBUNAL SUPERIOR ELEITORAL. Cronologia das Eleições no Brasil (1945 - 2010). Disponível em: <http://www.tse.jus.br/institucional/analisar-melhor-descarte/biblioteca-earquivo/eleitos-1945-1990/cronologia-das-eleicoes>. Acesso em 12 de fevereiro de 2016.

Artigo recebido em: 08/11/2017

Artigo aceito para publicação em: 05/12/2017 